\title{
(2) OPEN ACCESS \\ Healthy People Countdown 2030: reaching 5\% cigarette smoking prevalence among US adults through state cigarette excise tax increases
}

\author{
Nigar Nargis
}

\begin{abstract}
- Additional supplemental material is published online only. To view, please visit the journal online (http://dx.doi. org/10.1136/tobaccocontrol2021-056755)
\end{abstract}

Department of Surveillance and Health Equity Science, American Cancer Society, Atlanta, Georgia, USA

\section{Correspondence to} Dr Nigar Nargis, Department of Surveillance and Health Equity Science, American Cancer Society, Atlanta, GA, USA: nigar.nargis@cancer.org

Received 3 May 2021 Accepted 10 August 2021
Check for updates

(C) Author(s) (or their employer(s)) 2021. Re-use permitted under CC BY-NC. No commercial re-use. See rights and permissions. Published by BMJ.

To cite: Nargis N. Tob Control Epub ahead of print: [please include Day Month Year]. doi:10.1136/ tobaccocontrol-2021-056755

\begin{abstract}
Objective The Healthy People $2030 \mathrm{goal}$ is to reduce US current adult cigarette smoking prevalence to 5\% by 2030 . The objective of this report is to investigate if this goal is achievable using state cigarette excise tax increases.
\end{abstract}

Methods State-specific linear trends in smoking prevalence over 2011-2019 were determined using fractional logit regression and compared with the desired linear trends for achieving 5\% smoking prevalence by 2030 in individual states and the District of Columbia (DC). The gaps between price-adjusted and desired trends were used in a simulation model for identifying state-specific systematic annual increases in state cigarette excise tax rates based on state-specific price elasticity of smoking prevalence, maintaining the status quo in other non-tax tobacco control measures.

Results The price-adjusted trends in smoking prevalence observed over 2011-2019 exceed the desired trends for achieving 5\% smoking prevalence target by 2030 in only five states (eg, Washington, Utah, Rhode Island, Massachusetts and Maryland) and the DC. It suggests that majority of states and USA overall will miss the target smoking prevalence at the current rate of reduction in smoking. 45 states would need systematic annual increases in cigarette excise tax rate in a range of \$0.02-\$1.37 per pack over 2022-2030 to meet the target.

Conclusions The feasibility of reaching the Healthy People 2030 goal would critically depend on the acceleration of progress in tobacco control. Tax increases tailored to the needs of individual states combined with scaled-up non-tax tobacco control policy interventions can help achieve the desired progress.

\section{INTRODUCTION}

USA experienced two-thirds reduction in adult smoking prevalence from $42.4 \%$ to $13.7 \%$ over 1965-2018. ${ }^{1}$ The Healthy People goal is to reduce it to $5 \%$ by $2030 .^{2}$ The feasibility of achieving this goal is yet to be tested in view of the recent progress in tobacco control. In this report, state-specific trends in smoking prevalence over 2011-2019 were compared with the desired trends for achieving 5\% smoking prevalence by each state. The gaps between price-adjusted and desired trends were used as the basis for state-specific interventions through systematic annual increases in state cigarette excise tax, maintaining the status quo in non-tax tobacco control measures.

Previous research applied several microsimulation and macrosimulation models to project the effects of tobacco tax increases on population health and economic outcomes. ${ }^{3-12}$ Only one of these studies explored the potential of reaching the Healthy People 2010 goal of reducing smoking prevalence to $12 \%$ by simulating the combined effect of national level tax and price increase, smoke-free indoor air law, mass media campaign and cessation support. ${ }^{12}$ The present study simulates the effect of cigarette tax and price increases only in reducing adult cigarette smoking prevalence to $5 \%$ by 2030 . The major innovation in this paper is to make state-specific projections that can better inform state-level tobacco control interventions.

\section{METHODS}

The analysis was conducted in three stages in a simulation model using STATA (V.15; Stata) and Microsoft Excel. First, the existing trends in smoking prevalence in state $s$ in terms of average annual change in percentage points (pp) adjusted for price changes were determined using fractional logit regression (a generalised linear model for dependent variables bounded between 0 and 1) of smoking prevalence on the year variable and average state-level cigarette prices based on historical annual data from the Behavioral Risk Factor Surveillance System (BRFSS) and the Tax Burden on Tobacco (TBOT) database over 2011-2019. ${ }^{13-15}$ The regression equation estimated for each state separately is given by: $Y_{s t}=\alpha_{s p}+\beta_{s}^{e p} t+\beta_{s p} P_{s t}+v_{s t}$, where $Y_{s t}$ is adult cigarette smoking prevalence (\%) in state $\mathrm{s}$ in year $\mathrm{t}, \alpha_{s p}$ is the state-specific intercept, $\beta_{s}^{e p}$ represents the existing trend adjusted for the effects of price changes, $P_{s t}$ is the average cigarette price per pack in state $s$ in year $t, \beta_{s p}$ is the statespecific coefficient of price changes and $v_{\text {st }}$ is the random disturbance term and $t=2011,2012, \ldots$, 2019. Thus, the sample size for each regression run for individual states was nine to allow for nine data points between 2011 and 2019.

Second, the state-wise desired trends (in pp) were determined by the linear trend required to reduce smoking prevalence from the baseline level to the $5 \%$ target by 2030. Suppose the desired annual trend is $\beta_{s}^{d}$ pp. So, $Y_{s, 2021}-9 \beta_{s}^{d}=Y_{s, 2030}=5$ or $\beta_{s}^{d}=\left(Y_{s, 2021}-5\right) / 9$. The price-adjusted trends $\left(\beta_{s}^{e p}\right)$ were used to calculate the 'gap' $\left(\beta_{s}^{e p}-\beta_{s}^{d}\right)$.

Third, the marginal effects of price on smoking prevalence among US adults by age group estimated by Sloan and Trogdon based on BRFSS data for 1992-2002 were used to obtain average marginal effect size $\left.\beta_{1}\right)$ of -0.0096 for the overall population. ${ }^{16}$ It was then used to estimate 
state-specific price elasticity of smoking prevalence for each year as $C_{s t}=\beta_{1} \times\left(P_{s s} / Y_{s t}\right)$. Thus, the price elasticity estimates were adjusted for higher prices and lower smoking prevalence in each successive year. The price elasticity estimates in year $t$ were then used to estimate the required percentage increase in price to achieve the target reduction in smoking prevalence in year $t+1$ for each year from 2022 through 2030 using the formula:

$$
\frac{P_{s, t+1}-P_{s t}}{P_{s t}}=\frac{1}{\epsilon_{s t}} \frac{\left(\beta_{s}^{d}-\beta_{s}^{e p}\right)}{Y_{s t}}
$$

The year-on-year increase in price necessary to achieve a target reduction in smoking prevalence was then translated into yearon-year increase in state cigarette excise tax under the assumption of full pass-through of tax increase to price. In other words, $T A X_{s, t+1}=T A X_{s t}+\left(P_{s, t+1}-P_{s t}\right)$, where $T A X_{s t}$ is state cigarette excise tax per pack in state $s$ in year $t$.

The baseline for the projection of tax and price increases was set in 2021. The unadjusted trends in smoking prevalence estimated from the equation $Y_{\mathrm{st}}=\alpha_{\mathrm{s}}+\beta_{\mathrm{s}}{ }^{\mathrm{e}} t+u_{\mathrm{st}}$, where $\alpha_{s}$ is the state-specific intercept, $\beta_{\mathrm{s}}{ }^{\mathrm{e}}$ is the unadjusted trend in smoking prevalence in state $s$, and $u_{s t}$ is the random disturbance term, which were used to extrapolate from 2019 to initialise smoking prevalence in the baseline year 2021. The smoking prevalence in the baseline year 2021 was thus estimated using the equation: $Y_{s, 2021}=Y_{s, 2019}+2 \beta_{s}^{e}$, where $Y_{s, 2019}$ is the latest smoking prevalence data for state $s$ in 2019 available from the BRFSS. The unadjusted trend $\beta_{s}^{e}$ was multiplied with 2 to account for 2 years from 2019 to 2021. The projections were adjusted for tax increases in Colorado and Oregon in 2021 and in Virginia in 2020. The projections for Colorado and Oregon states were given by $Y_{s, 2021}=\left(Y_{s, 2019}+\beta_{\mathrm{s}}{ }^{e}\right)\left(1+\epsilon_{s, 2020} \times\left(P_{s, 2021}-P_{s, 2020}\right) / P_{s, 2020}\right)+\beta_{s}^{e p}$. The projection for Virginia was given by $Y_{s, 2021}=Y_{s, 2019}(1+$ $\left.\epsilon_{s, 2019} \times\left(P_{s, 2020}-P_{s, 2019}\right) / P_{s, 2019}\right)+\beta_{s}^{e p}+\beta_{s}^{e}$.

As TBOT data on tax and prices are available only up to 2019, the tax rates were updated up to the baseline year 2021 based on the announcements of tax increases by state revenue authorities. The state average cigarette prices for 2020 and 2021 were predicted based on a price regression given by: $P_{s t}=\gamma_{0}+\gamma_{1}$ $T A X_{s t}+\gamma_{2} E_{s t}+\gamma_{s}+\Sigma_{s} \gamma_{3} D_{s t}$, where $\gamma_{s}$ is the state fixed effect, $D_{s t}$ represents the state-specific time trend and $P_{s t}, T A X_{s t}$ and $E_{s t}$ are the price, tax and median earnings of state $s$ in year $t$ as defined before.

\section{RESULTS}

The baseline cigarette smoking prevalence varies widely from a low of $7.1 \%$ in Utah to $22.7 \%$ in West Virginia in 2021 (table 1). The price-adjusted trends over 2011-2019 also varies widely from $-1.13 \mathrm{pp}$ in the District of Columbia (DC) to $0.00 \mathrm{pp}$ in Hawaii and Montana. The desired annual trends varies from $-0.23 \mathrm{pp}$ in Utah to $-1.97 \mathrm{pp}$ in West Virginia. The priceadjusted trends exceed the desired trends for only five states (eg, Washington, Utah, Rhode Island, Massachusetts and Maryland) and the DC which are on target. Among the remaining states, California with a trend gap of $-0.02 \mathrm{pp}$ is closest to the target, while West Virginia with a trend gap of -1.31 pp needs to catch up most.

At the price-adjusted trends, the DC is projected to hit the lowest smoking prevalence of $0.5 \%$ while West Virginia will remain at the top at $16.8 \%$ by 2030 , bringing the state average (weighted by state adult population in 2019) price-adjusted expected smoking prevalence down from $13.6 \%$ in 2021 to $8.4 \%$ in 2030 .
Notes

- The smoking prevalence in the baseline year 2021 (column 2) was projected using the equation: Ys,2021 $=Y s, 2019+2 \beta \mathrm{s}^{\mathrm{e}}$, where Ys,2019 is the latest smoking prevalence data for state $s$ in 2019 available from the BRFSS, $\beta \mathrm{s}^{\mathrm{e}}$ is the unadjusted linear trend which is multiplied with 2 to account for 2 years from 2019 to 2021. The projections were adjusted for tax increases in Colorado and Oregon in 2021 and in Virginia in 2020. The projections for Colorado and Oregon states were given by $Y_{\mathrm{s}, 2021}=\left(Y_{\mathrm{s}, 2019}+\beta_{\mathrm{s}}{ }^{\mathrm{e}}\right)\left(1+\epsilon_{\mathrm{s}, 2020} \times(P \mathrm{~s}, 2021\right.$ - $P \mathrm{~s}, 2020) / P \mathrm{~s}, 2020)+\beta \mathrm{s}^{\mathrm{e} P}$. The projection for Virginia was given by $Y s, 2021=Y s, 2019(1+\epsilon s, 2019 \times(P s, 2020$ $-P \mathrm{~s}, 2019) / P \mathrm{~s}, 2019)+\beta \mathrm{s}^{\mathrm{ep}}+\beta \mathrm{s}^{\mathrm{e}}$.

- The price-adjusted expected smoking prevalence in 2030 (column 3) was calculated using the formula: $Y s, 2021=Y s, 2019+9 \beta \mathrm{s}^{\mathrm{ep}}$ accounting for linear trend over 9 years from 2021 to 2030 .

- The desired average annual changes $\left(\beta_{\mathrm{s}}{ }^{\mathrm{d}}\right)$ (column 4) were estimated using the formula: $\beta \mathrm{s}^{\mathrm{d}}=\left(\mathrm{Y}_{\mathrm{s}, 2021}-5\right) / 9$.

- The price-adjusted average annual changes $\left(\beta \mathrm{s}^{\mathrm{ep}}\right)$ (column 5 ) were estimated using the fractional logit regression: $Y \mathrm{st}=\alpha \mathrm{sp}+\beta \mathrm{s}^{\mathrm{ep}} t+\beta \mathrm{sp} P \mathrm{st}+v \mathrm{st}$.

- The state average cigarette prices for 2021 (column 7) were predicted based on the estimated price equation:

$$
P_{s t}=5.28^{* * *}+0.53^{* * *} T A X_{s t}+0.02 E_{s t}+\gamma_{s}+\Sigma_{s} \gamma_{3} D_{s t},
$$

where $\gamma_{s}$ is the state fixed effect, $D_{s t}$ represents the state-specific time trend, and $P_{s t}, T A X_{s t}$ and $E_{s t}$ are the price, tax and median earnings, respectively, of state $s$ in year $t . * *$ stands for significance at $1 \%$ level. Since the coefficient of the earnings variable is statistically insignificant, only the tax increases were considered for prediction.

- The price elasticity estimates for state $s$ in year $t(s t)$ were used to estimate the required percentage increase in price to achieve the target reduction in smoking prevalence in year $t+1$ for each year from 2022 through 2030 using the formula:

$$
\frac{P_{s, t+1}-P_{s t}}{P_{s t}}=\frac{1}{\epsilon_{s t}} \frac{\left(\beta_{s}^{d}-\beta_{s}^{e p}\right)}{Y_{s t}}
$$

The target prices for only 2030 are reported in column 8 for brevity of presentation.

- As TBOT data on tax and prices are available only up to 2019, the tax rates were updated up to the baseline year 2021 (column 9) based on the announcements of tax increases by state revenue authorities.

- The year-on-year increase in price necessary to achieve a target reduction in smoking prevalence was translated into year-on-year increase in state cigarette excise tax under the assumption of full pass-through of tax increase to price, that is, TAXs, $\mathrm{t}+1=\mathrm{TAXst}+(P \mathrm{~s}, \mathrm{t}+1-P \mathrm{st})$, where TAXst is state cigarette excise tax per pack in state $s$ in year $t$. The target tax rates for only 2030 are reported in column 10 for brevity of presentation.

- The price and tax in 2030 and corresponding price increases are not shown in this table for the states for which the priceadjusted trend $\left(\beta_{\mathrm{s}}^{\mathrm{ep}}\right)$ exceeded the desired trend $\left(\beta_{\mathrm{s}}{ }^{\mathrm{d}}\right)$.

The state-level estimates of price elasticity of smoking in 2021 vary from -0.25 in Kentucky to -0.93 in Utah. The statespecific price elasticity estimates by year from 2021 to 2029 are provided in online supplemental Table A1.

After adjustment for effects of price changes, 45 states were found in need of catching up with desired trends using tax increases. Based on the estimated elasticities, the required annual average cigarette excise tax increase ranges from $\$ 0.02$ 


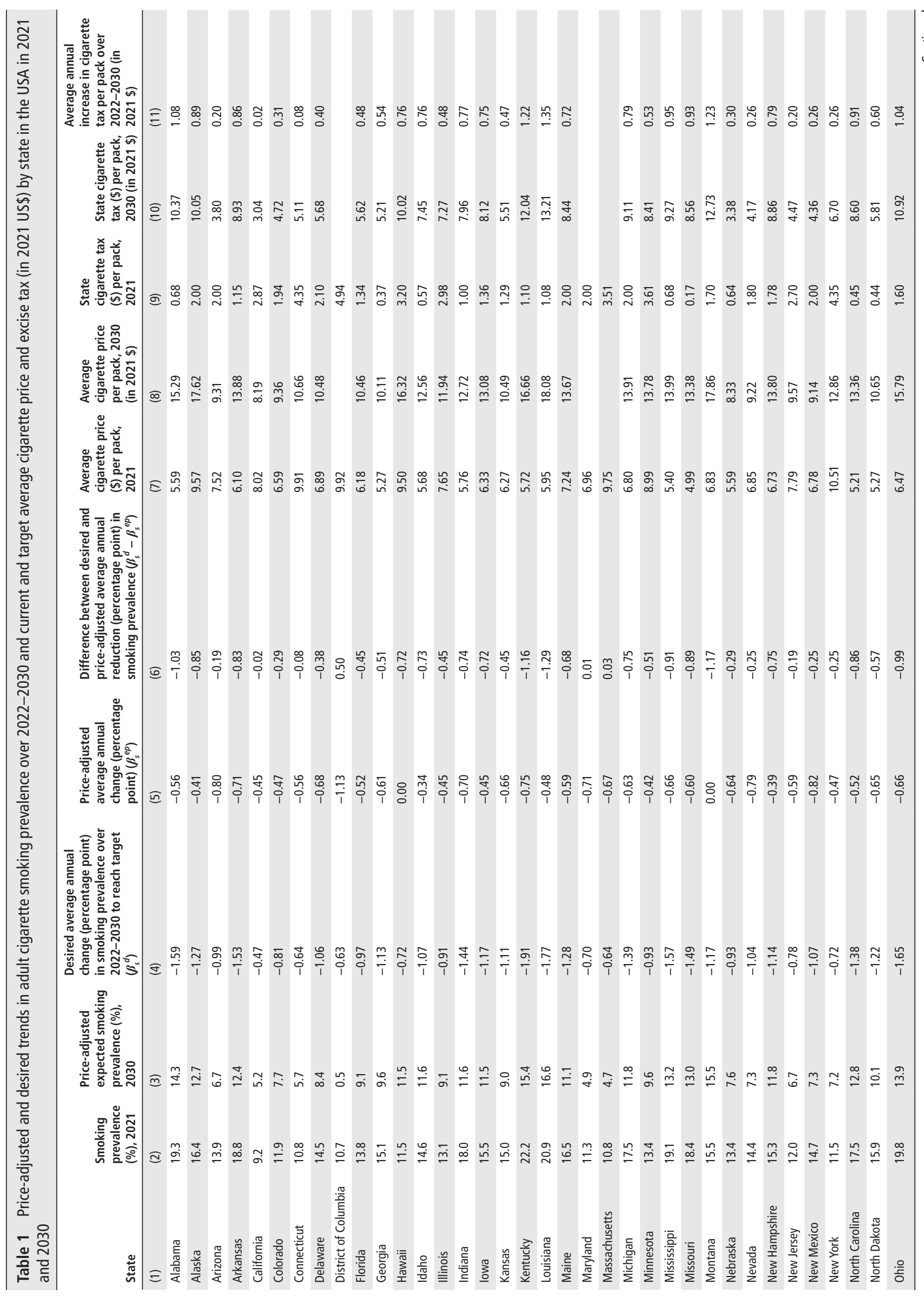



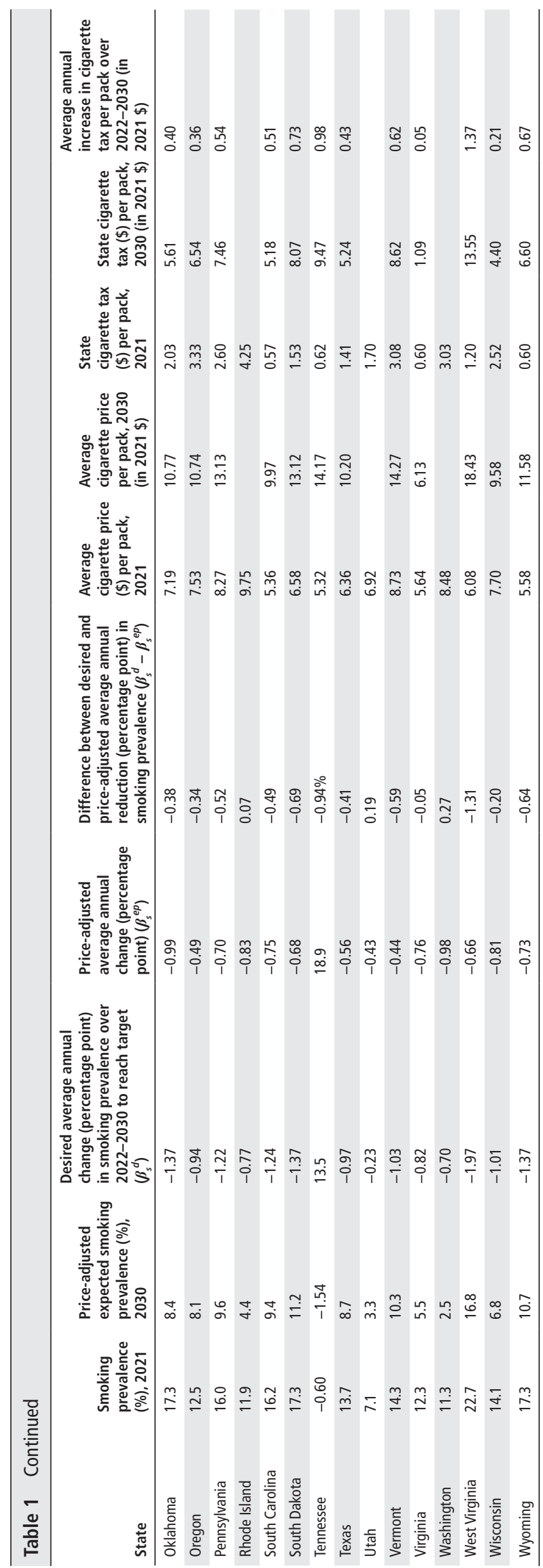

in California to $\$ 1.37$ in West Virginia in 2021. The current and target cigarette prices and excise tax rates per pack in 2021 and 2030 and annual average tax increases over 2022-2030 are presented by state in table 1 .

\section{DISCUSSION}

The findings in this report suggest that majority of states in the USA and the nation as a whole will miss the Healthy People 2030 target in the absence of accelerated progress in tobacco control measures through the most effective means. To meet the target smoking prevalence of $5 \%$ by 2030,45 states need systematic annual increases in state cigarette excise tax rates while continuing with other tobacco control measures. This requirement stands in sharp contrast with only 22 states increasing cigarette excise tax rates occasionally during 2011-2021. It suggests that cigarette excise tax policy has remained a severely underused measure of tobacco control despite its proven effectiveness in reducing smoking and related health disparities. ${ }^{17-20}$

The 2014 US Surgeon General's Report on the health consequences of smoking recommended raising average cigarette retail price to $\$ 10$ per-pack or higher across the nation as a key measure to reduce smoking. ${ }^{20}$ The state-level final prices in 2030 measured in this report as required to fill the 'gap' between the desired and the price-adjusted trends are higher than the recommended $\$ 10$ minimum in 35 states. These measures, however, refer to an 'unconstrained' scenario and do not necessarily reflect the feasible range of tax-induced price increases that may be subject to several political-economic constraints including parity in taxes and prices across states. The baseline state average cigarette prices range from $\$ 4.99$ to $\$ 10.51$ and the highest price is 2.10 times the lowest price. The desired state average price in 2030 ranges from $\$ 6.13$ to $\$ 18.43$ where the highest price is 3.01 times the lowest price. To keep the ratio between the lowest and the highest prices at the baseline level, the highest price can be capped at $\$ 12.87(=\$ 6.13 \times 2.10)$. There are 21 states that have desired prices in 2030 above this cap and that may need to scale up non-tax tobacco control policy interventions to make up for the 'gap'.

One major limitation of this study is that it is restricted to tax policy interventions only. The underlying assumption here is that the acceleration of reduction in smoking prevalence would be attained by price increases only. Stronger comprehensive tobacco control measures in addition to tax-induced price increases would imply that the tax and price increases required for the target reduction in smoking prevalence would be lower than those projected in this model. The model thus predicts the upper bound of the tax and price increases for the desired outcome.

During the observation period under study from 2011 to 2019 , the federal cigarette tax was not changed. As a result, it was not possible to quantify the effect of a federal tax increase and account for potential federal tax increases in the analysis. Should the federal cigarette tax increase over the projection period of 2022-2030, the required state-level tax increases would be lower than the levels computed in this report.

The tax and price increases envisioned to contribute to the tobacco endgame in the USA are not meant to deny the unintended and adverse financial consequences for the smokers who are unable to quit, specifically among those in the disadvantaged communities. There might be other political-economic constraints, such as increased cross-state cigarette purchases or stronger tobacco industry lobbying resisting tax policy interventions, that can potentially undermine the intended effects 
of such measures. It is, therefore, crucial to scale up non-tax tobacco control measures targeted to disadvantaged communities, harmonise tax and price across neighbouring states and monitor and counter tobacco industry interference to mitigate these unintended consequences of tax and price increases. ${ }^{21}$

\section{CONCLUSION}

The feasibility of reaching the Healthy People 2030 goal of attaining 5\% adult smoking prevalence by 2030 would critically depend on the acceleration of progress in tobacco control. Cigarette tax policy has remained severely underused in mitigating the disease burden of smoking in the US. Tax increases tailored to the needs of individual states with scaled-up non-tax tobacco control measures can help achieve the desired progress.

\section{What this paper adds}

\section{What is already known on this subject}

- Smoking causes illnesses among more than 16 million adults and nearly half a million premature deaths in the USA annually.

- The Healthy People 2030 goal is to reduce current adult cigarette smoking prevalence to $5 \%$ by 2030 .

- The 2014 US Surgeon General's Report recommended raising average cigarette retail price to $\$ 10$ per-pack or higher across the nation as a key measure to reduce smoking.

What important gaps in knowledge exist on this topic

- The feasibility of achieving the Healthy People $2030 \mathrm{goal}$ is yet to be tested in view of the recent progress in tobacco control made in the USA.

- Previous research explored the potential of reaching the Healthy People goal by simulating the combined effect of tax and price increase, smoke-free indoor air law, mass media campaign and cessation support at the national level. Far less is known about how state-level tobacco control interventions can be tailored to help achieve a target level of smoking prevalence across all US states.

What this paper adds

- In the USA, 45 states need systematic annual increases in cigarette excise tax rate in a range of $\$ 0.02-\$ 1.37$ per pack over 2022-2030 to meet the 5\% smoking prevalence target.

- Tax increases tailored to the needs of individual states with scaled-up non-tax interventions can help achieve the desired progress in tobacco control.

Acknowledgements The author benefitted greatly from the comments of the participants during the e-poster presentation of this report at the Society for Research on Nicotine and Tobacco Research (SRNT) Virtual Annual Meeting, 24-27 February 2021 and the oral presentation at the International Health Economic Association (iHEA) Congress, 12-15 July 2021. The author would also like to acknowledge the feedback received from her colleagues at the American Cancer Society that helped improved the manuscript to a great extent. The author is thankful to three anonymous reviewers for their valuable comments.

Contributors NN designed the study, analysed data, drafted and revised the manuscript.

Funding The authors have not declared a specific grant for this research from any funding agency in the public, commercial or not-for-profit sectors.
Competing interests No, there are no competing interests.

Patient consent for publication Not required.

Provenance and peer review Not commissioned; externally peer reviewed.

Open access This is an open access article distributed in accordance with the Creative Commons Attribution Non Commercial (CC BY-NC 4.0) license, which permits others to distribute, remix, adapt, build upon this work non-commercially, and license their derivative works on different terms, provided the original work is properly cited, appropriate credit is given, any changes made indicated, and the use is non-commercial. See: http://creativecommons.org/licenses/by-nc/4.0/.

\section{ORCID iD}

Nigar Nargis http://orcid.org/0000-0003-4501-1398

\section{REFERENCES}

1 National Center for Health Statistics. National health interview survey. Hyattsville, MD: US Department of Health and Human Services, CDC, National Center for Health Statistics, 1965-2018.

2 United States Department of Health and Human Services. Healthy people 2030. office of disease prevention and health promotion, 2020. Available: https://health.gov/ healthypeople/objectives-and-data/browse-objectives/tobacco-use/reduce-currentcigarette-smoking-adults-tu-02 [Accessed 21 Apr 2021].

3 Emery S, Ake CF, Navarro AM, et al. Simulated effect of tobacco Tax variation on Latino health in California. Am J Prev Med 2001;21:278-83.

4 Ahmad S. Increasing excise taxes on cigarettes in California: a dynamic simulation of health and economic impacts. Prev Med 2005;41:276-83.

5 Kaplan RM, Ake CF, Emery SL, et al. Simulated effect of tobacco Tax variation on population health in California. Am J Public Health 2001;91:239-44.

6 Levy DT, Friend K. Examining the effects of tobacco treatment policies on smoking rates and smoking related deaths using the SimSmoke computer simulation model. Tob Control 2002:11:47-54.

7 Ahmad S, Franz GA. Raising taxes to reduce smoking prevalence in the US: a simulation of the anticipated health and economic impacts. Public Health 2008;122:3-10.

8 Levy DT, Boyle RG, Abrams DB. The role of public policies in reducing smoking: the Minnesota SimSmoke tobacco policy model. Am J Prev Med 2012;43:S179-86.

9 Feirman SP, Donaldson E, Glasser AM, et al. Mathematical modeling in tobacco control research: initial results from a systematic review. Nicotine Tob Res 2016;18:229-42.

10 Feirman SP, Glasser AM, Rose $S$, et al. Computational models used to assess US tobacco control policies. Nicotine Tob Res 2017;19:1257-67.

11 Tam J, Levy DT, Jeon J, et al. Projecting the effects of tobacco control policies in the USA through microsimulation: a study protocol. BMJ Open 2018;8:e019169.

12 Levy DT, Mabry PL, Graham AL, et al. Reaching healthy people 2010 by 2013. Am J Prev Med 2010;38:S373-81.

13 Papke LE, Wooldridge JM. Panel data methods for fractional response variables with an application to test pass rates. J Econom 2008;145:121-33.

14 Centers for Disease Control and Prevention. National center for chronic disease prevention and health promotion, division of population health. behavioral risk factor surveillance system. 2011-2018. Available: http://www.cdc.gov/brfss [Accessed 12 Nov 2020].

15 Orzechowski and Walker. Tax burden on tobacco, 1970-2019. Available: https:// chronicdata.cdc.gov/Policy/The-Tax-Burden-on-Tobacco-1970-2019/7nwe-3aj9 [Accessed 12 Nov 2020].

16 Sloan FA, Trogdon JG. The impact of the master settlement agreement on cigarette consumption. J Policy Anal Manage 2004;23:843-55.

17 Baum A, Aguilar-Gomez S, Lightwood J, et al. Estimating the long-run relationship between state cigarette taxes and County life expectancy. Tob Control 2020;29:81-8

18 Keeler C, Max W, Yao T, et al. Smoking behavior in low- and high-income adults immediately following California proposition 56 tobacco Tax increase. Am J Public Health 2020;110:868-70.

19 CDC. Reducing tobacco use: a report of the surgeon General. Atlanta, GA: US Department of Health and Human Services, CDC, 2000. http://www.cdc.gov/tobacco/ data_statistics/sgr/2000/complete_report/index.htm

20 US Department of Health and Human Services. The health consequences of smoking - 50 years of progress: a report of the surgeon General. Atlanta, GA: US Department of Health and Human Services, CDC, 2014. https://www.cdc.gov/tobacco/ data_statistics/sgr/50th-anniversary/index.htm

21 Hirono KT, Smith KE. Australia's \$40 per pack cigarette tax plans: the need to consider equity. Tob Control 2018;27:229-33. 